\title{
The role of $\alpha$-synuclein in the pathophysiology of alcoholism
}

\author{
7 Q2 Paulina Janeczek, Joanne M. Lewohl*
}

Griffith Health Institute, School of Medical Sciences, Griffith University, Gold Coast Campus, Southport, Australia

\section{A R T I C L E I N F O}

\section{Article history:}

Received 29 January 2013

Received in revised form 6 June 2013

Accepted 8 June 2013

Available online $\mathrm{xxxx}$

\section{Keywords:}

SNCA

mRNA

Splice variant

MicroRNA

\begin{abstract}
A B S T R A C T
Alcoholism has complex etiology and there is evidence for both genetic and environmental factors in its pathophysiology. Chronic, long-term alcohol abuse and alcohol dependence are associated with neuronal loss with the prefrontal cortex being particularly susceptible to neurotoxic damage. This brain region is involved in the development and persistence of alcohol addiction and neurotoxic damage is likely to exacerbate the reinforcing effects of alcohol and may hinder treatment. Understanding the mechanism of alcohol's neurotoxic effects on the brain and the genetic risk factors associated with alcohol abuse are the focus of current research. Because of its well-established role in neurodegenerative and neuropsychological disorders, and its emerging role in the pathophysiology of addiction, here we review the genetic and epigenetic factors involved in regulating $\alpha$-synuclein expression and its potential role in the pathophysiology of chronic alcohol abuse. Elucidation of the mechanisms of $\alpha$-synuclein regulation may prove beneficial in understanding the role of this key synaptic protein in disease and its potential for therapeutic modulation in the treatment of substance use disorders as well as other neurodegenerative diseases.
\end{abstract}

(c) 2013 Published by Elsevier Ltd.

\section{Contents}

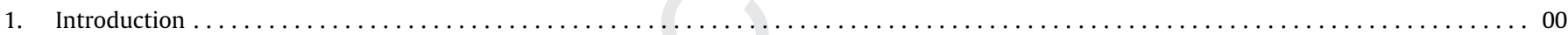

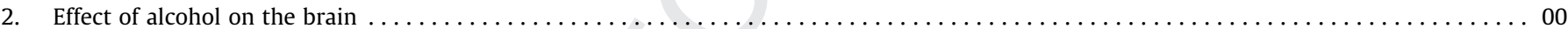

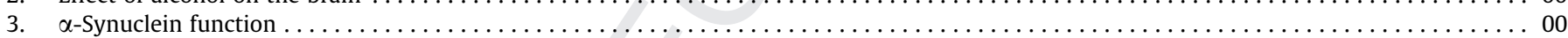

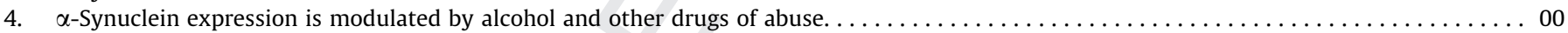

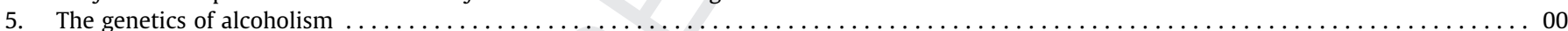

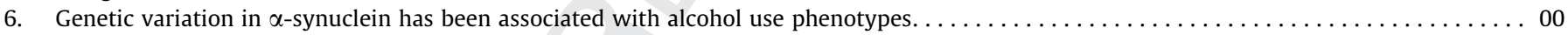

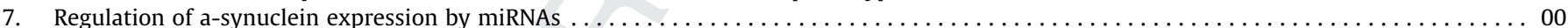

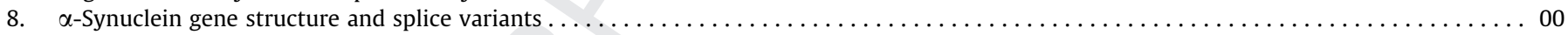

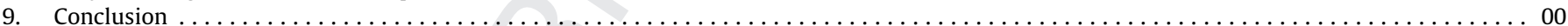

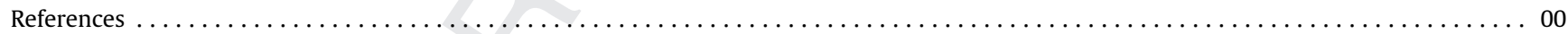

\section{Introduction}

Alcoholism is a complex, multi-factorial disorder with substantial health, societal and economic consequences worldwide. The World Health Organization estimates that alcohol abuse contributes $\sim 5 \%$ to the global burden of disease and results in 2.5 million deaths annually (WHO, 2004). Furthermore, excessive alcohol consumption results in 69 million Disability-Adjusted Life Years ${ }^{1}$

\footnotetext{
* Corresponding author. Address: School of Medical Science, Gold Coast Campus, Griffith University 4222, Australia. Tel.: +61 75552 7096; fax: +61 755528908.

E-mail address: j.lewohl@griffith.edu.au (J.M. Lewohl).

${ }^{1}$ The Disability-Adjusted Life Year (DALY) is used by the WHO as a measure of the potential years of life lost due to premature death and the equivalent years of 'healthy' life lost by being in a state of poor health and disability. One year of equivalent full health is represented by one DALY (WHO, 2013).
}

(DALYs) around the world (WHO, 2004). Approximately one third of the deaths are due to unintentional injuries and almost $40 \%$ of the DALYs are the result of neuropsychiatric conditions. Disability due to alcohol abuse has been ranked the third leading risk factor for DALYs and the eighth risk factor for premature death. Although drinking patterns, societal influences and consumption rates vary between countries, regions and communities, there is a constant negative outcome for the health of individuals who choose to abuse alcohol (WHO, 2004).

\section{Effect of alcohol on the brain}

Although alcohol affects many organs in the body, a major target is the brain where long-term abuse results in neuropathological damage (Harper, 2009). This damage is not uniform; rather, 
particular regions of the brain are more affected than others (Kril et al., 1997). For example, in the cerebral cortex, neuronal loss occurs in the dorsolateral prefrontal cortex whereas other regions of the cortex, such as the primary motor cortex, are relatively spared (Harper and Kril, 1989). Loss of brain weight and white matter in particular, has been shown to be associated with the severity of alcohol abuse (de la Monte, 1988; Harding et al., 1996; Harper and Kril, 1985). The damage to the brain results in memory loss, impairment in conceptualisation, processing of complex material, planning and abstract thought. Neuropathological abnormalities, including damage to the structure and function of the brain, are greater in alcoholics with cirrhosis of the liver or vitamin B1 deficiency (Zahr et al., 2011).

Continuous exposure to alcohol, results in changes in neuronal function which are mediated, at least in part, by changes in gene expression (Nestler and Aghajanian, 1997). Recent studies, particularly those utilizing global gene and protein expression profiling techniques, have focused on understanding the adaptive response of neurons in the prefrontal cortex. These studies have identified a number of synaptic genes and proteins which are differentially regulated in the prefrontal cortex of human alcoholics (Etheridge et al., 2009; Lewohl et al., 2004, 2000; Liu et al., 2004, 2007, 2006; Mayfield et al., 2002); one of these is $\alpha$-synuclein, a gene with a well-characterized role in the pathophysiology of Parkinson disease.

\section{3. $\alpha$-Synuclein function}

The role of $\alpha$-synuclein in neurodegeneration has been the focus of a number of studies following its identification as the non-amyloid component of senile plaques and as the major protein component of Lewy bodies (Iwai et al., 1995; Spillantini and Goedert, 2000). In both sporadic and familial Parkinson disease, the $\alpha$-synuclein protein does not fold correctly, forming insoluble and dysfunctional protein aggregates resulting in a loss of dopaminergic neurons (Junn et al., 2009; Kahle et al., 2001; Spillantini and Goedert, 2000).

$\alpha$-Synuclein is abundantly expressed in neurons where it is found predominantly in presynaptic terminals (Iwai et al., 1995; Jakes et al., 1994; Withers et al., 1997; Zhang et al., 2008). While the exact function of $\alpha$-synuclein is unknown, a number of studies have shown it to have a role in mediating dopaminergic neurotransmission including synthesis, storage, release and reuptake of the neurotransmitter (Baptista et al., 2003; Yavich et al., 2004). Under normal conditions, $\alpha$-synuclein negatively regulates the uptake of dopamine by the dopamine transporter in line with its expression levels. Specifically, $\alpha$-synuclein suppression reduces the surface expression and maximal uptake velocity of the dopamine transporter and has been shown to result in dopamine-induced apoptosis (Fountaine and Wade-Martins, 2007; Lee et al., 2001; Wersinger and Sidhu, 2003). Interestingly, $\alpha$-synuclein plays a dual role in neurotoxicity and in neuroprotection that is dependent on its expression levels, with both low and high levels of expression resulting in cytotoxicity (Seo et al., 2002). Up-regulation of $\alpha$-synuclein occurs in response to oxidative stress and excitotoxicity, hence, its normal physiological role may be to protect neuronal cells against damage (Sidhu et al., 2004).

Changes in $\alpha$-synuclein expression, which affect the reuptake of dopamine, are likely to alter dopamine-mediated neuronal signalling. It has been suggested that dopaminergic neurotransmission is the main mediator of craving, withdrawal, and the reinforcement pathways in alcohol addiction (Self and Nestler, 1998). Thus, altered expression of $\alpha$-synuclein may affect the function of the dopaminergic reward pathway. Neurons in this pathway project to the dorsolateral prefrontal cortex, the brain region responsible for executive functions that are disrupted following chronic alcohol abuse in human subjects (Koob and Volkow, 2010). The absence of $\alpha$-synuclein has been shown to increase the sensitivity of the brain reward system; suggesting that an individual may be predisposed to various psychiatric diseases or drug abuse according to the levels of $\alpha$-synuclein in their brain (Oksman et al., 2006).

$\alpha$-Synuclein has been shown to interact with membranes (Fortin et al., 2004) and lipids (Jo et al., 2000), and dysfunction can lead to defects in mitochondrial function, lipid/sterol biosynthesis, the stress response and endoplasmic reticulum to Golgi complex trafficking (Auluck et al., 2010). A study by Scott and Roy (2012) suggests that $\alpha$-synuclein may have a role in maintaining recycling pool homeostasis and regulating synaptic vesicle trafficking. It has been suggested that $\mathrm{Ca}^{2+}$ entry pathways may be regulated by $\alpha$-synuclein, and that changes to normal $\alpha$-synuclein expression could affect $\mathrm{Ca}^{2+}$ homeostasis and cause neuronal damage (Hettiarachchi et al., 2009).

$\alpha$-Synuclein also functions as a molecular chaperone due to its structural homology to the 14-3-3 family of proteins (Ostrerova et al., 1999; Tzivion et al., 1998). This idea is supported by the findings that $\alpha$-synuclein interacts with many regulatory proteins involved in dopamine homeostasis at the axon terminals, is regulated during development and up-regulated during neuronal plasticity (George et al., 1995; Petersen et al., 1999).

Some studies have suggested that alcohol consumption may have a protective effect on Parkinson disease, however this correlation needs to be investigated further (Grandinetti et al., 1994; Hernan et al., 2003; Noyce et al., 2012; Paganini-Hill, 2001). Other addictive behaviours; like drinking coffee and smoking have been associated with decreased risk of Parkinson disease (Hernan et al., 2001; Morozova et al., 2008; O'Reilly et al., 2009; Thacker et al., 2007). It is thought that an individual who will develop Parkinson disease may be less susceptible to becoming addicted to substances (Menza, 2000). A number of studies have investigated the correlation of the risk of Parkinson and alcohol consumption and either show no change or a moderately decreased risk of Parkinson disease (Behari et al., 2001; Benedetti et al., 2000; Fall et al., 1999; Gorell et al., 1999; Hellenbrand et al., 1996; Jimenez-Jimenez et al., 1992; Liou et al., 1997; Morano et al., 1994; Palacios et al., 2012). There are a number of known limitations in case-control studies that may compound the findings; therefore these results should be interpreted with caution.

Two missense mutations; A53T and A30P in the $\alpha$-synuclein gene have been found to cause familial Parkinson disease (Kruger et al., 1998; Polymeropoulos et al., 1997). Idiopathic Parkinson disease has been associated with various polymorphisms in the a-synuclein $5^{\prime}$ non-coding region (Kruger et al., 1999; Tan et al., 2000). Many of these variations have also been associated with increased risk in alcoholism including the SNCA-Rep1 microsatellite repeat (Janeczek et al., 2012). It is well documented that the longer alleles of the SNCA-Rep1 dinucleotide repeat are correlated with Parkinson disease (Cronin et al., 2009; Maraganore et al., 2006). Although the studies are inconsistent, it has been shown that variations in the SNCA promoter are also correlated with alcohol abuse, and that alcohol use disorders are inversely correlated with Parkinson disease (Bonsch et al., 2005b; Brighina et al., 2009; Chiba-Falek et al., 2003).

\section{4. $\alpha$-Synuclein expression is modulated by alcohol and other drugs of abuse}

Differential expression of $\alpha$-synuclein may contribute to increased alcohol consumption in rats selectively bred for 
199 increased alcohol preference (Liang et al., 2003). These rats

exhibited a two-fold increase in the expression of $\alpha$-synuclein in the hippocampus and caudate-putamen compared with alcoholnonpreferring rats (Liang and Carr, 2006). Other brain regions, such as the striatum, show decreased levels of expression (Carr et al., 2006). Furthermore, alcohol-naïve inbred alcohol-preferring rats had lower expression levels of $\boldsymbol{\alpha}$-synuclein transcripts in the frontal cortex compared with congenic P.NP rats in which the alcohol preferring QTL on chromosome 4, containing the SNCA gene, was replaced by the equivalent QTL from the inbred non-preferring rat line (Liang et al., 2010). Interestingly, the difference in expression was specific for the frontal cortex. These studies only measured the basal expression of $\alpha$-synuclein and did not investigate the effect of alcohol exposure on the expression of the gene. However, a single polymorphic variant in the 3'-untranslated region ( $3^{\prime}$-UTR) of alcohol-preferring rats is likely to be responsible for the differences in expression (Liang and Carr, 2006).

The expression of $\alpha$-synuclein is also regulated by alcohol exposure in both animal models and humans. The expression of $\alpha$-synuclein was elevated in the blood of primates that self-administer alcohol compared with alcohol-naïve controls (Walker and Grant, 2006) as well as in mice following withdrawal from chronic alcohol drinking (Ziolkowska et al., 2008). In human studies, both $\alpha$-synuclein transcript and protein levels are elevated in serum from actively drinking and recently withdrawn alcoholics and are correlated with craving in these individuals (Bonsch et al., 2005a, 2004). $\alpha$-Synuclein is also elevated in response to other drugs of abuse, including cocaine (Mash et al., 2008, 2003; Qin et al., 2005) and amphetamine (Fornai et al., 2005). Whether this up-regulation occurs as a direct result of long-term drug abuse, or reflects an increase in the basal expression of $\alpha$-synuclein in these individuals, remains to be elucidated. Only one study has specifically measured the expression of $\alpha$-synuclein in the brain of human alcoholics (Janeczek et al., 2012). This study reported lowered expression of $\alpha$-synuclein in the dorsolateral prefrontal cortex of alcoholics compared with controls. Microarray (Lewohl et al., 2000) and proteomic (Lewohl et al., 2004) studies have also shown that $\alpha$-synuclein is differentially regulated in this brain region suggesting it may play a role in neuroadaptations to long-term alcohol abuse. $\alpha$-Synuclein may play a protective role in neurons. It is expressed in response to apoptotic signals, oxidative stress, and excitotoxicity (Sidhu et al., 2004). Lower levels of $\alpha$-synuclein may therefore put neurons at risk of the neurotoxic effects of alcohol due to a loss of its inherent neuroprotective effects. Since $\alpha$ synuclein also plays a role in trafficking of neurotransmitter transporters, neurons with lowered $\alpha$-synuclein levels may lose the ability to adapt to the continual presence of alcohol in the brain (Yavich et al., 2004).

A key question is whether blood levels of $\alpha$-synuclein reflect changes in expression in brain. To date, only one study has correlated $\alpha$-synuclein expression in both brain tissue and blood from the same individuals. Ziolkowska et al. (2008) used a chronic alcohol drinking mouse model to show that $\alpha$-synuclein transcript levels increased in the blood $48 \mathrm{~h}$ after withdrawal, as had been shown previously in humans and monkeys. However, these levels did not correlate to the expression of $\alpha$-synuclein in the brain, where protein expression peaked $24 \mathrm{~h}$ after withdrawal. This finding suggests that there is little or no correlation between $\alpha$-synuclein expression levels in blood and brain but further studies are required.

\section{The genetics of alcoholism}

Alcoholism has a complex etiology and there is evidence for both genetic and environmental factors in the pathophysiology of the condition. Family, adoption and twin studies have concluded that alcoholism has an estimated heritability of $\sim 50 \%$ (Ducci and Goldman, 2008; Mayfield et al., 2008). The genetics of alcohol abuse and alcoholism is not straightforward. Large-scale family studies and case-control association studies have identified many chromosomal regions and polymorphic variants that influence alcoholism risk and related phenotypes (Ducci and Goldman, 2008; Mayfield et al., 2008). It is likely that several genes contribute to the susceptibility of an individual to each phenotype, with each gene having a small but additive effect. Hence, an individual's susceptibility to alcohol abuse and alcoholism may be determined by genes influencing their acute sensitivity to alcohol intoxication, the development of tolerance to, and dependence on, alcohol, and the development of intense desire for alcohol or 'craving'. Genetic factors may also underlie the neuroadaptive changes that occur in response to chronic alcohol abuse. Thus, an individual's genotype may underlie gene expression differences. For example, changes in the expression of $G A B A_{A}$ subunit transcripts are among the most marked alterations in human alcoholic prefrontal cortex (Dodd and Lewohl, 1998 ; Lewohl et al., 1997, 2001) and these effects may be moderated by genotype, including polymorphisms in the dopamine receptor DRD2 gene (Buckley et al., 2006). Furthermore, the TaqIA polymorphism within the ANKK1 gene selectively modulates NMDA receptor transcript expression in the prefrontal cortex of cirrhotic-alcoholics compared with controls (Ridge et al., 2008). Recent evidence suggests that the same is true for the $\alpha$-synuclein gene.

\section{Genetic variation in $\alpha$-synuclein has been associated with alcohol use phenotypes}

Whole-genome linkage analyses have mapped alcohol dependence and related phenotypes to a region on chromosome 4 containing a cluster of genes for alcohol dehydrogenase ( $A D H 1 B$ and $A D H 1 C)$ and $\alpha$-synuclein (SNCA) (Ehlers et al., 2004; Reich et al., 1998; Saccone et al., 2000; Williams et al., 1999). The syntenic chromosomal region has been linked to a quantitative trait locus (QTL) for alcohol consumption in rats selectively bred for high alcohol preference (Liang et al., 2003).

The SNCA gene is highly polymorphic, and the association between sequence variation in SNCA and neurodegenerative disorders such as Parkinson disease has been well documented. Sequence variation occurs within the SNCA gene itself, as well as in the SNCA-Rep1 region, which is a microsatellite repeat, approximately $10 \mathrm{~kb}$ upstream from the translation start site (Touchman et al., 2001). Five alleles have been identified based on a size difference of 2 nucleotides ( 265 bp, 267 bp, 269 bp, 271 bp, and 273 bp). SNCA-Rep1 is necessary for normal expression and increasing allele lengths correlate with increased expression levels in neuroblastoma cell lines (Chiba-Falek and Nussbaum, 2001).

Polymorphisms in SNCA-Rep1 are associated with alcohol use phenotypes, including alcohol abuse, alcohol dependence and craving although the findings are inconsistent. Bonsch et al. (2005b) found a significant increase in the frequency of the longer alleles (273 bp and $271 \mathrm{bp}$ ) in alcohol-dependent individuals that were correlated with increased expression of $\alpha$-synuclein in the same cases. In comparison, Janeczek et al. (2012) found that an increased frequency of the shorter $267 \mathrm{bp}$ allele was correlated with reduced expression of $\alpha$-synuclein in the dorsolateral prefrontal cortex of long-term alcohol abusers. Other polymorphisms have also been associated with alcohol use phenotypes with eight SNPs distributed in the $5^{\prime}$ and $3^{\prime}$ ends of the gene found to be associated with a sub-population of alcohol-dependent individuals (42\%) who experienced craving (Foroud et al., 2007). In these individuals, a haplotype block in the $3^{\prime}$-UTR of the gene was over-transmitted 


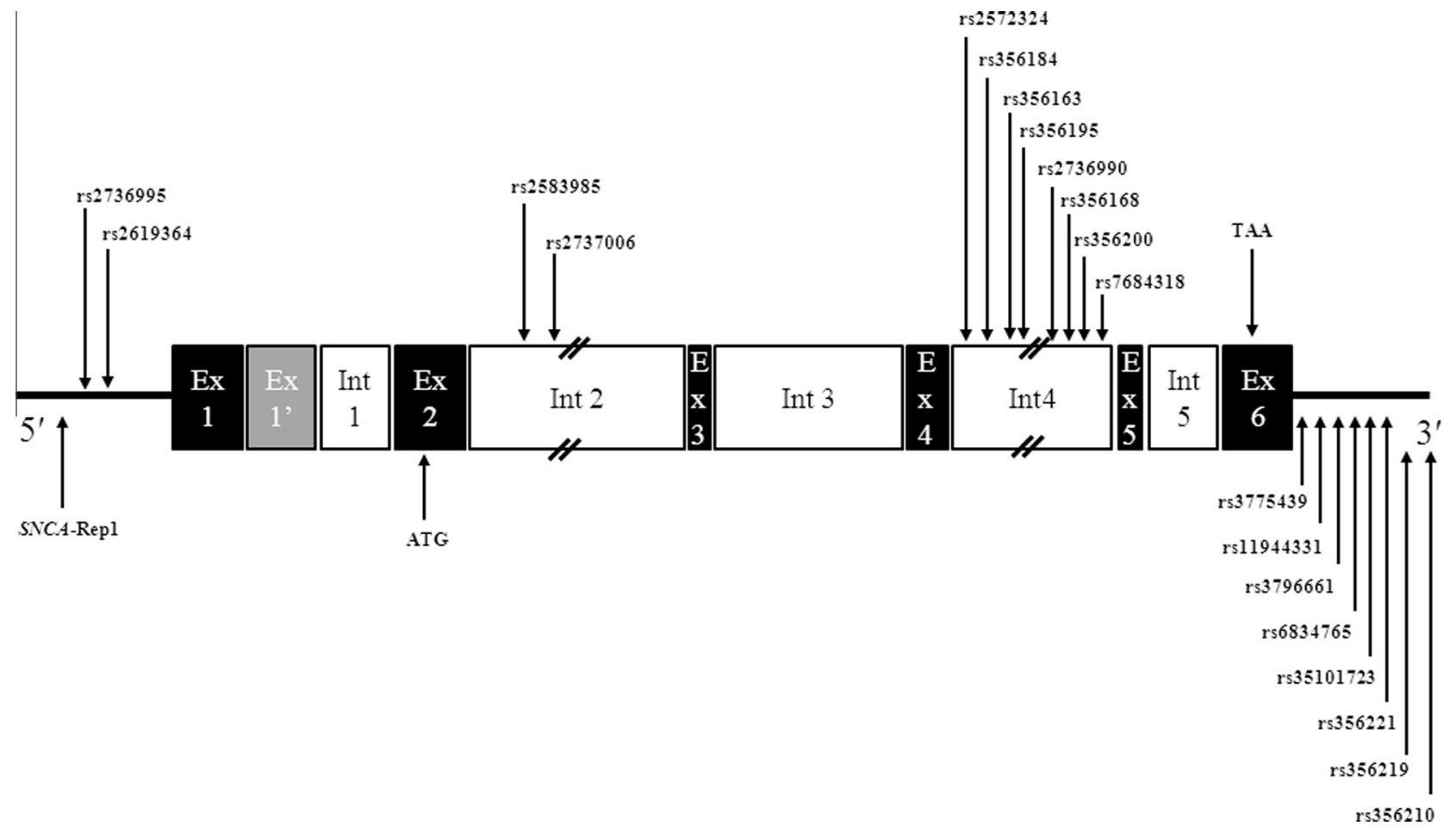

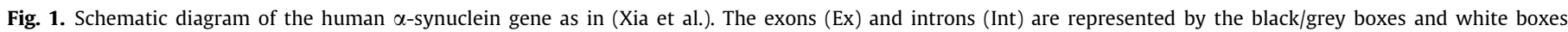

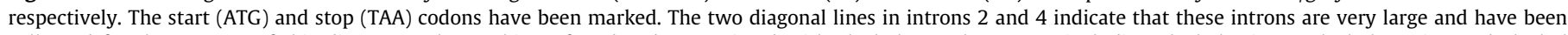

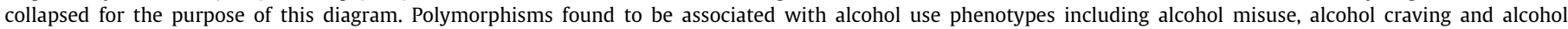
dependence have been indicated (Agrawal et al., 2012; Bonsch et al., 2005b; Clarimon et al., 2007; Foroud et al., 2007; Janeczek et al., 2012).

to individuals who craved alcohol whereas the complementary haplotype was over-transmitted to individuals who did not crave alcohol. Fig. 1 details the location of the single nucleotide polymorphisms and microsatellite repeat markers that have been shown to be associated with alcohol use disorders in previous studies.

Genetic variation in the 5'- and 3'-UTRs has also been correlated with expression levels of the gene (Bonsch et al., 2005b; ChibaFalek and Nussbaum, 2001; Sotiriou et al., 2009). For example, Poly-(ADP-ribose) transferase/polymerase-1 (PARP-1), a nuclear DNA-binding protein (Newman et al., 2002), binds directly to the SNCA-Rep1 region (Chiba-Falek et al., 2005). When bound to SNCA-Rep1, PARP-1 decreased the activity of the SNCA promoter. Conversely, inhibition of PARP-1 resulted in an increase in the expression of $\alpha$-synuclein transcripts. SNCA-Rep 1 is necessary for normal expression and increasing allele lengths correlate with increased expression levels in neuroblastoma cell lines (Chiba-Falek and Nussbaum, 2001). Thus, it is likely that sequence variation in the SNCA-Rep1 microsatellite alters the binding parameters of PARP-1 thereby altering the transcription of the gene. The effect of genetic variation in the $3^{\prime}$-UTR on the expression of SNCA is likely to be the result of regulation of expression by microRNAs (miRNAs).

\section{Regulation of a-synuclein expression by miRNAs}

MiRNAs are short non-coding RNAs that regulate gene expression by targeting specific sequences in the 3'-UTR of many genes. MiRNAs function as endogenous repressors preventing translation of target mRNAs, ultimately determining the protein profile of the cell. The primary miRNAs are transcribed within the nucleus and then processed into shorter precursor miRNAs. These precursor miRNAs are transported to the cytosol within the RNA-induced silencing complex (RISC) and bind to their target mRNAs. The sequence can be complementary or partially complementary to the target site. Once the miRNA binds to the mRNA, translation is inhibited or the mRNA is degraded (Bushati and Cohen, 2008).

miRNAs are highly abundant in brain and critically affect brain development and neuronal differentiation. More recently, miRNAs have been shown to play roles in synapse formation and plasticity (Schratt et al., 2006), neuronal survival (Schaefer et al., 2007), as well as in human disease (Bushati and Cohen, 2008).

Recent studies have shown that miRNAs may mediate cellular adaptions to alcohol exposure in cell culture models, animal models of alcohol dependence as well as human alcoholics. A study by Tapocik et al. (2012) found that the expression of specific miRNAs and their corresponding mRNA targets were dysregulated in the medial prefrontal cortex of rats with a history of alcohol dependence. Alcohol-responsive miRNAs have also been identified in murine primary neuronal cultures (Guo et al., 2012), in fetal neural stem cells (Balaraman et al., 2012; Sathyan et al., 2007), fetal mouse brain (Wang et al., 2009) and in neuroblastoma cell lines (Van Steenwyk et al., 2013; Yadav et al., 2011) following chronic alcohol exposure and its withdrawal. Furthermore, 35 miRNAs were found to be significantly up-regulated in the prefrontal cortex of human alcoholics compared with controls (Lewohl et al., 2011). A summary of the alcohol-responsive miRNAs identified in humans, rodents and cell culture models is given in Table 1 . The predicted targets for these miRNAs showed a large degree of overlap with down-regulated genes identified in previous cDNA microarray studies (Liu et al., 2006). In general, these results suggest that up-regulation of miRNAs in the prefrontal cortex of human alcoholics may contribute to the deterioration and concomitant adaptation of neuronal functioning observed in cases of alcohol abuse. The overlap between putative 
Table 1

Comparison of differentially expressed miRNAs in humans, rats and mice.

\begin{tabular}{|c|c|c|c|c|}
\hline miRNA ID & Human & Rat & Mouse & Refs. \\
\hline miR-553 & $\uparrow$ & & & \\
\hline miR-369-3p & $\uparrow \uparrow^{*}$ & & & Yadav et al. (2011) \\
\hline miR-18a & $\uparrow$ & $\uparrow$ & & Tapocik et al. (2012) \\
\hline miR-339 & $\uparrow$ & & $\downarrow$ & Wang et al. (2009) \\
\hline miR-1 & $\uparrow$ & & & \\
\hline $\operatorname{miR}-7$ & $\uparrow \uparrow \uparrow^{* * *} \downarrow$ & $\downarrow$ & & Tapocik et al. (2012), Van Steenwyk et al. (2013) \\
\hline miR-196a & $\uparrow$ & & & \\
\hline miR-301 & $\uparrow$ & $\downarrow$ & & Tapocik et al. (2012) \\
\hline miR-144 & $\uparrow \downarrow^{* * *}$ & & & Van Steenwyk et al. (2013) \\
\hline let-7g & $\uparrow$ & & & \\
\hline miR-153 & $\uparrow \uparrow^{* *} \downarrow \uparrow^{* * *}$ & & $\downarrow^{* * * * * *}$ & Balaraman et al. (2012), Sathyan et al. (2007), Van Steenwyk et al. (2013) \\
\hline let-7f & $\uparrow$ & & & \\
\hline miR-203 & $\uparrow \downarrow \uparrow * * * \downarrow^{* * *} \downarrow^{* *}$ & & & Van Steenwyk et al. (2013) \\
\hline miR-34 & $\uparrow \uparrow * \uparrow * * * * *$ & & & Yadav et al. (2011) \\
\hline miR-101 & $\uparrow$ & & & \\
\hline miR-376 & $\uparrow$ & $\downarrow$ & & Tapocik et al. (2012) \\
\hline miR-665 & $\uparrow$ & & & \\
\hline miR-152 & $\uparrow \uparrow^{* * *} \downarrow \uparrow^{* *}$ & & $\uparrow \uparrow^{* *}$ & Wang et al. (2009), van Steenwyk et al. (2013), Guo et al. (2012) \\
\hline miR-194 & $\uparrow$ & & & \\
\hline miR-423-5p & $\uparrow$ & & & \\
\hline miR-515-3p & $\uparrow$ & & & \\
\hline miR-374 & $\uparrow$ & $\downarrow$ & & Tapocik et al. (2012) \\
\hline miR-140 & $\uparrow$ & & $\downarrow^{* * * * *}$ & Balaraman et al. (2012) \\
\hline miR-519b-3p & $\uparrow$ & & & 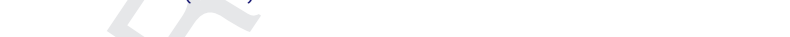 \\
\hline miR-586 & $\uparrow$ & & & \\
\hline miR-135b & $\uparrow$ & & & \\
\hline miR-92a & $\uparrow$ & & & \\
\hline miR-15 & $\uparrow \downarrow \uparrow^{* * *} \downarrow^{* * *}$ & & $\uparrow \uparrow^{* *}$ & Van Steenwyk et al. (2013), Guo et al. (2012) \\
\hline miR-580 & $\uparrow$ & & & \\
\hline miR-146a & $\uparrow$ & & & \\
\hline miR-454-3p & $\uparrow$ & & & \\
\hline miR-380 & $\uparrow$ & & & \\
\hline miR-652 & $\uparrow$ & & & \\
\hline miR-802 & $\uparrow$ & & & \\
\hline miR-196b & $\uparrow$ & & & \\
\hline
\end{tabular}

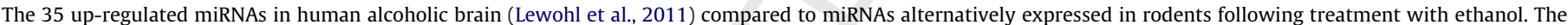

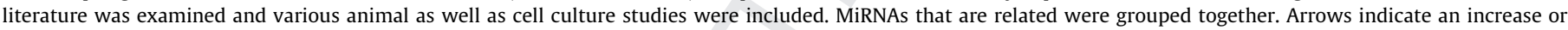

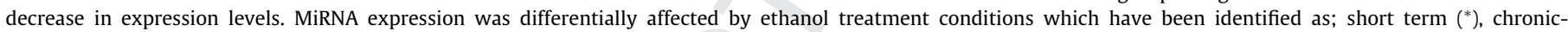
intermittent $\left({ }^{* *}\right)$, withdrawal $\left({ }^{* * *}\right)$, long term $\left({ }^{* * * *}\right)$, high dose $\left(^{* * * * *}\right)$.

targets of miRNAs and the differentially expressed genes from previous studies provides information on the biological functions and networks of genes regulated by specific miRNAs in human alcoholism (Lewohl et al., 2011).

Several of the known alcohol-responsive miRNAs are predicted to target $\alpha$-synuclein and this interaction has been verified for miR-7 and miR-153. MiR-7 (hsa-miR-7; MIMAT0000252), a miRNA predominately expressed in neurons, has been shown to regulate $\alpha$-synuclein, by binding to the 3 '-UTR and repressing its translation in a dose-dependent manner (Junn et al., 2009). MiR-153 (hsa-miR153; MIMAT0000439), down-regulates $\alpha$-synuclein mRNA and protein levels post-transcriptionally, by binding to the specific sites on the $3^{\prime}$-UTR (Doxakis, 2010). Thus, miR-7 acts by inhibiting the translation of $\alpha$-synuclein where as miR-153 acts by promoting the degradation of the mRNA, and they work synergistically to lower $\alpha$-synuclein levels. This proposed regulatory pathway for the control of $\alpha$-synuclein expression may also be affected by genetic variation.

Polymorphisms in the miRNA binding site can eliminate or enhance the binding affinity a miRNA has for its target or create a new illegitimate binding site, changing the way the target gene is regulated. Therefore, mutations in miRNA binding sites can alter target gene expression in many different ways and provides evidence of another form of gene regulation that can influence the risk of an individual developing a disease (Chen et al., 2008; Georges et al., 2007). This has been shown in other diseases, for example the $3^{\prime}$-UTR of the SLITRK1 gene, thought to be involved in Tourette's syndrome, was found to contain a SNP that increased the strength of the miR-189 target site, resulting in down-regulation of the corresponding protein (Abelson et al., 2005). Although this example shows that a polymorphism may have a more direct role in causing a disease, it is unlikely for this to be the case for the majority. In contrast to a loss or gain of function due to genetic variation, it is more likely that the mutations affecting the miRNA-target interactions in addiction pathways will have gradual phenotypic consequences, due to a "fine tuning" approach to gene regulation rather than complete suppression (Georges et al., 2007). One of the mechanisms by which gene expression can be "fine-tuned" is through the differential regulation of splice variants.

Pietrzykowski et al. (2008) showed that alcohol, acting via a specific miRNA, miR-9, regulates the expression of alternatively spliced mRNAs encoding the large-conductance calcium- and voltage-activated potassium channel (BK), which is a known target of alcohol's actions in mediating molecular alcohol tolerance. Alcohol caused a rapid up-regulation in miR-9 expression, resulting in selective degradation of BK mRNAs containing a miR-9 target site in their 3'-UTRs. The selective degradation of some splice variants but not others altered the profile of BK channels, consistent with the development of tolerance to alcohol (Pietrzykowski et al., 2008). This represents a new mechanism of gene regulation of splice variants that may underlie the neuroadaptive changes that occur at a cellular level to long-term alcohol exposure. 
SNCA-140 ENST00000394986

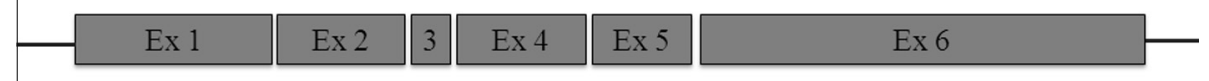

SNCA-126 ENST00000394989

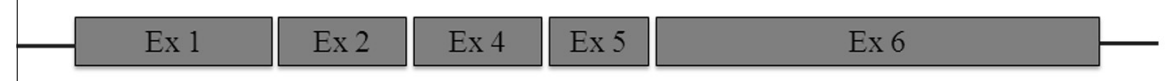

SNCA-115 ENST00000502987

\begin{tabular}{|l|l|l|l|l|}
\hline Ex 1 & Ex 2 & 3 & Ex 4 & Int 4 \\
\hline
\end{tabular}

SNCA-112 ENST00000420646

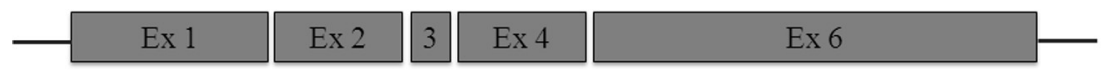

SNCA-98 ENST00000394986

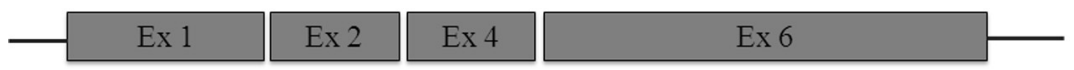

Fig. 2. Structure of five human $\alpha$-synuclein transcripts. The exons (Ex) and intron (Int) 4 are represented by the grey boxes and white box respectively.

\section{8. $\alpha$-Synuclein gene structure and splice variants}

SNCA is approximately $117 \mathrm{~kb}$ in length and has been mapped to chromosome position 4q21.3-22 (Touchman et al., 2001; Xia et al., 1996) (Fig. 1). Human $\alpha$-synuclein exists in at least four distinct splice variants that produce functional polypeptides (Fig. 2). The full-length (wildtype) sequence encodes a 140 amino acid protein comprised of 6 exons. The other three variants are exon-skipping variants: the 126 amino acid variant is missing exon 3; the 112 amino acid variant is missing exon 5; and the newly identified 98 amino acid variant is missing both exons 3 and 5 (Beyer et al., 2009, 2008). The online Ensembl database (www.ensembl.org) predicts a total of 11 transcript variants. Five of these variant transcripts encode the wildtype 140 amino acid polypeptide, two encode the 126 amino acid variant and two encode the 112 amino acid variant. The variant corresponding to the 98 amino acid splice variant is not listed in this database. The different forms of each of these alternative transcripts differ primarily in their $5^{\prime}$ and $3^{\prime}$ regulatory regions. In particular, the $3^{\prime}$-UTR of each of these variants differs in length, however $95 \%$ of the SNCA variants have the first $574 \mathrm{bp}$ in common (Sotiriou et al., 2009). Differences in miRNA binding sites within the 3'-UTR of each of the splice variants may regulate the way each of the variants are expressed.

Two additional alternative transcripts are predicted in the Ensembl database. One of these, designated SNCA-67 (ENST000005066691), is predicted to encode a 67 amino acid polypeptide containing exons 1-3 and the first 36 nucleotides of exon 4 however the sequence is incomplete at the $3^{\prime}$ end. The second predicted transcript, designated SNCA-115 (ENST00000502987) encodes a 115 amino acid polypeptide that includes exons 1-4 and the first 393 nucleotides of intron 4. It is important to note that this variant has a completely unique $3^{\prime}$-UTR regulatory region which is found in intron 4 , and therefore has the potential to be regulated by different miRNAs.

\section{Conclusion}

$\alpha$-Synuclein is an abundantly expressed neuronal protein with a well-documented role in neurodegenerative disorders such as Parkinson and Alzheimer disease. The normal physiological function of this key protein is likely to be in the regulation of dopaminergic neurotransmission and as such, it has been identified as a candidate gene for substance abuse and alcoholism. Most notably, recent studies have shown that the expression of $\alpha$-synuclein is modulated by chronic, long-term alcohol exposure (Janeczek et al., 2012) and can also be correlated with craving in alcohol-dependent individuals (Bonsch et al., 2004). Furthermore, sequence variation in SNCA-Rep1 is associated with alcohol use phenotypes and can be correlated with expression levels of the gene (Bonsch et al., 2005b; Janeczek et al., 2012) although the studies conducted to date have yielded conflicting results. $\alpha$-Synuclein expression is also regulated by miRNAs in particular miR-7 and miR-153; these miRNAs are altered by chronic alcohol abuse (Lewohl et al., 2011).

$\alpha$-Synuclein exists in a number of known and predicted splice variants. However, none of the studies performed to date have measured the expression of individual transcript or protein variants in alcoholics. Since the known $\alpha$-synuclein splice variants differ in the length of their $3^{\prime}$-UTRs, the miRNAs that target them may differ, leading to selected degradation of some variants but not others in a manner similar to that proposed for the BK channel (Pietrzykowski et al., 2008). Alternatively, polymorphisms in the 3'-UTR have the potential to alter miRNA target sites, thereby disrupting the regulation of specific splice variants. In this way, sequence variation in the $3^{\prime}$-UTR may predispose individuals to the toxic effects of chronic alcohol abuse through a miRNA-mediated mechanism. Future research towards understanding the mechanism of $\alpha$-synuclein regulation may provide insights into the mechanism of alcohol's neurotoxic effects on the brain and may identify new therapeutic targets for the treatment of substance use disorders as well as neurodegenerative diseases.

\section{References}

Abelson, J.F., Kwan, K.Y., O’Roak, B.J., Baek, D.Y., Stillman, A.A., Morgan, T.M., Mathews, C.A., Pauls, D.L., Rasin, M.R., Gunel, M., Davis, N.R., Ercan-Sencicek, A.G., Guez, D.H., Spertus, J.A., Leckman, J.F., Dure, L.St., Kurlan, R., Singer, H.S. Gilbert, D.L., Farhi, A., Louvi, A., Lifton, R.P., Sestan, N., State, M.W., 2005 Sequence variants in SLITRK1 are associated with Tourette's syndrome. Science 310, 317-320.

Agrawal, A., Wetherill, L., Bucholz, K.K., Kramer, J., Kuperman, S., Lynskey, M.T. Nurnberger Jr., J.I., Schuckit, M., Tischfield, J.A., Edenberg, H.J., Foroud, T., Bierut, L.J., 2012. Genetic influences on craving for alcohol. Addict. Behav. 38, 15011508.

Auluck, P.K., Caraveo, G., Lindquist, S., 2010. Alpha-Synuclein: membrane interactions and toxicity in Parkinson's disease. Annu. Rev. Cell Dev. Biol. 26, 211-233. 
Balaraman, S., Winzer-Serhan, U.H., Miranda, R.C., 2012. Opposing actions of ethanol and nicotine on microRNAs are mediated by nicotinic acetylcholine receptors in fetal cerebral cortical-derived neural progenitor cells. Alcohol. Clin. Exp. Res. 36, 1669-1677.

Baptista, M.J., O’Farrell, C., Daya, S., Ahmad, R., Miller, D.W., Hardy, J., Farrer, M.J., Cookson, M.R., 2003. Co-ordinate transcriptional regulation of dopamine synthesis genes by alpha-synuclein in human neuroblastoma cell lines. J. Neurochem. 85, 957-968.

Behari, M., Srivastava, A.K., Das, R.R., Pandey, R.M., 2001. Risk factors of Parkinson's disease in Indian patients. J. Neurol. Sci. 190, 49-55.

Benedetti, M.D., Bower, J.H., Maraganore, D.M., McDonnell, S.K., Peterson, B.J., Ahlskog, J.E., Schaid, D.J., Rocca, W.A., 2000. Smoking, alcohol, and coffee consumption preceding Parkinson's disease: a case-control study. Neurology $55,1350-1358$

Beyer, K., Domingo-Sabat, M., Humbert, J., Carrato, C., Ferrer, I., Ariza, A., 2008. Differential expression of alpha-synuclein, parkin, and synphilin-1 isoforms in Lewy body disease. Neurogenetics 9, 163-172.

Beyer, K., Domingo-Sabat, M., Ariza, A., 2009. Molecular pathology of Lewy body diseases. Int. J. Mol. Sci. 10, 724-745.

Bonsch, D., Reulbach, U., Bayerlein, K., Hillemacher, T., Kornhuber, J., Bleich, S., 2004. Elevated alpha synuclein mRNA levels are associated with craving in patients with alcoholism. Biol. Psychiatry 56, 984-986.

Bonsch, D., Greifenberg, V., Bayerlein, K., Biermann, T., Reulbach, U., Hillemacher, T. Kornhuber, J., Bleich, S., 2005a. Alpha-synuclein protein levels are increased in alcoholic patients and are linked to craving. Alcohol. Clin. Exp. Res. 29, 763-765.

Bonsch, D., Lederer, T., Reulbach, U., Hothorn, T., Kornhuber, J., Bleich, S., 2005b. Joint analysis of the NACP-REP1 marker within the alpha synuclein gene concludes association with alcohol dependence. Hum. Mol. Genet. 14, 967-971.

Brighina, L., Schneider, N.K., Lesnick, T.G., de Andrade, M., Cunningham, J.M. Mrazek, D., Rocca, W.A., Maraganore, D.M., 2009. Alpha-synuclein, alcohol use disorders, and Parkinson disease: a case-control study. Parkinsonism Relat. Disord. 15, 430-434.

Buckley, S.T., Foley, P.F., Innes, D.J., Loh, E.-W., Shen, Y., Williams, S.M., Harper, C.G., Tannenberg, A.E.G., Dodd, P.R., 2006. $\mathrm{GABA}_{\mathrm{A}}$ receptor $^{\circledR}$ isoform protein expression in human alcoholic brain: interaction with genotype. Neurochem. Int. 49, 557-567.

Bushati, N., Cohen, S.M., 2008. MicroRNAs in neurodegeneration. Curr. Opin. Neurobiol. 18, 292-296.

Carr, L.G., Habegger, K., Spence, J.P., Liu, L., Lumeng, L., Foroud, T., 2006. Development of congenic rat strains for alcohol consumption derived from the alcohol-preferring and nonpreferring rats. Behav. Genet. 36, 285-290.

Chen, K., Song, F., Calin, G.A., Wei, Q., Hao, X., Zhang, W., 2008. Polymorphisms in microRNA targets: a gold mine for molecular epidemiology. Carcinogenesis 29 , 1306-1311.

Chiba-Falek, O., Nussbaum, R.L., 2001. Effect of allelic variation at the NACP-Rep1 repeat upstream of the alpha-synuclein gene (SNCA) on transcription in a cell culture luciferase reporter system. Hum. Mol. Genet. 10, 3101-3109.

Chiba-Falek, O., Touchman, J.W., Nussbaum, R.L., 2003. Functional analysis of intraallelic variation at NACP-Rep1 in the alpha-synuclein gene. Hum. Genet. 113 426-431.

Chiba-Falek, O., Kowalak, J.A., Smulson, M.E., Nussbaum, R.L., 2005. Regulation of alpha-synuclein expression by poly (ADP ribose) polymerase-1 (PARP-1) binding to the NACP-Rep1 polymorphic site upstream of the SNCA gene. Am. J. Hum. Genet. 76, 478-492.

Clarimon, J., Gray, R.R., Williams, L.N., Enoch, M.A., Robin, R.W., Albaugh, B Singleton, A., Goldman, D., Mulligan, C.J., 2007. Linkage disequilibrium and association analysis of alpha-synuclein and alcohol and drug dependence in two American Indian populations. Alcohol. Clin. Exp. Res. 31, 546-554.

Cronin, K.D., Ge, D., Manninger, P., Linnertz, C., Rossoshek, A., Orrison, B.M., Bernard, D.J., El-Agnaf, O.M., Schlossmacher, M.G., Nussbaum, R.L., Chiba-Falek, O., 2009. Expansion of the Parkinson disease-associated SNCA-Rep1 allele upregulates human alpha-synuclein in transgenic mouse brain. Hum. Mol. Genet. 18, 32743285.

de la Monte, S.M., 1988. Disproportionate atrophy of cerebral white matter in chronic alcoholics. Arch. Neurol. 45, 990-992.

Dodd, P.R., Lewohl, J.M., 1998. Cell death mediated by amino acid transmitter receptors in human alcoholic brain damage: conflicts in the evidence. Ann. N. Y. Acad. Sci. 844, 50-58.

Doxakis, E., 2010. Post-transcriptional regulation of alpha-synuclein expression by mir-7 and mir-153. J. Biol. Chem., epub ahead of print.

Ducci, F., Goldman, D., 2008. Genetic approaches to addiction: genes and alcohol. Addiction 103, 1414-1428.

Ehlers, C.L., Gilder, D.A., Wall, T.L., Phillips, E., Feiler, H., Wilhelmsen, K.C., 2004. Genomic screen for loci associated with alcohol dependence in Mission Indians Am. J. Med. Genet. B Neuropsychiatr. Genet. 129B, 110-115.

Etheridge, N., Lewohl, J.M., Mayfield, R.D., Harris, R.A., Dodd, P.R., 2009. Synaptic proteome changes in the superior frontal gyrus and occipital cortex of the alcoholic brain. Proteomics Clin. Appl. 3, 730-742.

Fall, P.A., Fredrikson, M., Axelson, O., Granerus, A.K., 1999. Nutritional and occupational factors influencing the risk of Parkinson's disease: a case-control study in southeastern Sweden. Mov. Disord. 14, 28-37.

Fornai, F., Lenzi, P., Ferrucci, M., Lazzeri, G., di Poggio, A.B., Natale, G., Busceti, C.L. Biagioni, F., Giusiani, M., Ruggieri, S., Paparelli, A., 2005. Occurrence of neuronal inclusions combined with increased nigral expression of alpha-synuclein within dopaminergic neurons following treatment with amphetamine derivatives in mice. Brain Res. Bull. 65, 405-413.
Foroud, T., Wetherill, L.F., Liang, T., Dick, D.M., Hesselbrock, V., Kramer, J., Nurnberger, J., Schuckit, M., Carr, L., Porjesz, B., Xuei, X., Edenberg, H.J., 2007. Association of alcohol craving with alpha-synuclein (SNCA). Alcohol. Clin. Exp. Res. 31, 537-545.

Fortin, D.L., Troyer, M.D., Nakamura, K., Kubo, S., Anthony, M.D., Edwards, R.H., 2004. Lipid rafts mediate the synaptic localization of alpha-synuclein. J. Neurosci. 24, 6715-6723.

Fountaine, T.M., Wade-Martins, R., 2007. RNA interference-mediated knockdown of alpha-synuclein protects human dopaminergic neuroblastoma cells from $\operatorname{MPP}(+)$ toxicity and reduces dopamine transport. J. Neurosci. Res. 85, 351-363.

George, J.M., Jin, H., Woods, W.S., Clayton, D.F., 1995. Characterization of a novel protein regulated during the critical period for song learning in the zebra finch. Neuron 15, 361-372.

Georges, M., Coppieters, W., Charlier, C., 2007. Polymorphic miRNA-mediated gene regulation: contribution to phenotypic variation and disease. Curr. Opin. Genet. Dev. 17, 166-176.

Gorell, J.M., Rybicki, B.A., Johnson, C.C., Peterson, E.L., 1999. Smoking and Parkinson's disease: a dose-response relationship. Neurology 52, 115-119.

Grandinetti, A., Morens, D.M., Reed, D., MacEachern, D., 1994. Prospective study of cigarette smoking and the risk of developing idiopathic Parkinson's disease. Am. J. Epidemiol. 139, 1129-1138.

Guo, Y., Chen, Y., Carreon, S., Qiang, M., 2012. Chronic intermittent ethanol exposure and its removal induce a different mirna expression pattern in primary cortical neuronal cultures. Alcohol. Clin. Exp. Res. 36, 1058-1066.

Harding, A.J., Halliday, G.M., Ng, J.L., Harper, C.G., Kril, J.J., 1996. Loss of vasopressinimmunoreactive neurons in alcoholics is dose-related and time-dependent. Neuroscience 72, 699-708.

Harper, C., 2009. The neuropathology of alcohol-related brain damage. Alcohol Alcohol. 44, 136-140.

Harper, C., Kril, J., 1985. Brain atrophy in chronic alcoholic patients: a quantitative pathological study. J. Neurol. Neurosurg. Psychiatry 48, 211-217.

Harper, C., Kril, J., 1989. Patterns of neuronal loss in the cerebral cortex in chronic alcoholic patients. J. Neurol. Sci. 92, 81-89.

Hellenbrand, W., Boeing, H., Robra, B.P., Seidler, A., Vieregge, P., Nischan, P., Joerg, J., Oertel, W.H., Schneider, E., Ulm, G., 1996. Diet and Parkinson's disease. II: A possible role for the past intake of specific nutrients. Results from a selfadministered food-frequency questionnaire in a case-control study. Neurology $47,644-650$.

Hernan, M.A., Zhang, S.M., Rueda-deCastro, A.M., Colditz, G.A., Speizer, F.E., Ascherio, A., 2001. Cigarette smoking and the incidence of Parkinson's disease in two prospective studies. Ann. Neurol. 50, 780-786.

Hernan, M.A., Chen, H., Schwarzschild, M.A., Ascherio, A., 2003. Alcohol consumption and the incidence of Parkinson's disease. Ann. Neurol. 54, 170-175.

Hettiarachchi, N.T., Parker, A., Dallas, M.L., Pennington, K., Hung, C.C., Pearson, H.A., Boyle, J.P., Robinson, P., Peers, C., 2009. Alpha-Synuclein modulation of Ca2+ signaling in human neuroblastoma (SH-SY5Y) cells. J. Neurochem. 111, 1192-1201.

Iwai, A., Yoshimoto, M., Masliah, E., Saitoh, T., 1995. Non-A beta component of Alzheimer's disease amyloid (NAC) is amyloidogenic. Biochemistry 34, 1013910145.

Jakes, R., Spillantini, M.G., Goedert, M., 1994. Identification of two distinct synucleins from human brain. FEBS Lett. 345, 27-32.

Janeczek, P., Mackay, R.K., Lea, R.A., Dodd, P.R., Lewohl, J.M., 2012. Reduced expression of alpha-synuclein in alcoholic brain: influence of SNCA-Rep1 genotype. Addict. Biol.

Jimenez-Jimenez, F.J., Mateo, D., Gimenez-Roldan, S., 1992. Premorbid smoking, alcohol consumption, and coffee drinking habits in Parkinson's disease: a casecontrol study. Mov. Disord. 7, 339-344.

Jo, E., McLaurin, J., Yip, C.M., St George-Hyslop, P., Fraser, P.E., 2000. AlphaSynuclein membrane interactions and lipid specificity. J. Biol. Chem. 275, 34328-34334.

Junn, E., Lee, K.W., Jeong, B.S., Chan, T.W., Im, J.Y., Mouradian, M.M., 2009. Repression of alpha-synuclein expression and toxicity by microRNA-7. Proc. Natl. Acad. Sci. USA 106, 13052-13057.

Kahle, P.J., Neumann, M., Ozmen, L., Muller, V., Odoy, S., Okamoto, N., Jacobsen, H., Iwatsubo, T., Trojanowski, J.Q., Takahashi, H., Wakabayashi, K., Bogdanovic, N., Riederer, P., Kretzschmar, H.A., Haass, C., 2001. Selective insolubility of alphasynuclein in human Lewy body diseases is recapitulated in a transgenic mouse model. Am. J. Pathol. 159, 2215-2225.

Koob, G.F., Volkow, N.D., 2010. Neurocircuitry of addiction. Neuropsychopharmacology 35, 217-238.

Kril, J.J., Halliday, G.M., Svoboda, M.D., Cartwright, H., 1997. The cerebral cortex is damaged in chronic alcoholics. Neuroscience 79, 983-998.

Kruger, R., Kuhn, W., Muller, T., Woitalla, D., Graeber, M., Kosel, S., Przuntek, H., Epplen, J.T., Schols, L., Riess, O., 1998. Ala30Pro mutation in the gene encoding alpha-synuclein in Parkinson's disease. Nat. Genet. 18, 106-108.

Kruger, R., Vieira-Saecker, A.M., Kuhn, W., Berg, D., Muller, T., Kuhnl, N., Fuchs, G.A., Storch, A., Hungs, M., Woitalla, D., Przuntek, H., Epplen, J.T., Schols, L., Riess, O., 1999. Increased susceptibility to sporadic Parkinson's disease by a certain combined alpha-synuclein/apolipoprotein E genotype. Ann. Neurol. 45, 611-617.

Lee, F.J., Liu, F., Pristupa, Z.B., Niznik, H.B., 2001. Direct binding and functional coupling of alpha-synuclein to the dopamine transporters accelerate dopamineinduced apoptosis. Faseb J. 15, 916-926.

610

611

612

614

615

617

618

619
620

621

622

624
625

626

627
628

629

630
631

632

633
634

635

636

637
638

639

640
641

642

643

645

646

648

649
650

651

653

654

656

657

658
659 
Lewohl, J.M., Crane, D.I., Dodd, P.R., 1997. Expression of the alpha 1, alpha 2 and alpha 3 isoforms of the GABAA receptor in human alcoholic brain. Brain Res. $751,102-112$

Lewohl, J.M., Wang, L., Miles, M.F., Zhang, L., Dodd, P.R., Harris, R.A., 2000. Gene expression in human alcoholism: microarray analysis of frontal cortex. Alcohol. Clin. Exp. Res. 24, 1873-1882.

Lewohl, J.M., Huygens, F., Crane, D.I., Dodd, P.R., 2001. GABA(A) receptor alphasubunit proteins in human chronic alcoholics. J. Neurochem. 78, 424-434.

Lewohl, J.M., Van Dyk, D.D., Craft, G.E., Innes, D.J., Mayfield, R.D., Cobon, G., Harris, R.A., Dodd, P.R., 2004. The application of proteomics to the human alcoholic brain. Ann. N. Y. Acad. Sci. 1025, 14-26.

Lewohl, J.M., Nunez, Y.O., Dodd, P.R., Tiwari, G.R., Harris, R.A., Mayfield, R.D., 2011. Up-Regulation of MicroRNAs in brain of human alcoholics. Alcohol. Clin. Exp. Res. 35, 1928-1937.

Liang, T., Carr, L.G., 2006. Regulation of alpha-synuclein expression in alcoholpreferring and -non preferring rats. J. Neurochem. 99, 470-482.

Liang, T., Spence, J., Liu, L., Strother, W.N., Chang, H.W., Ellison, J.A., Lumeng, L., Li, T.K., Foroud, T., Carr, L.G., 2003. Alpha-Synuclein maps to a quantitative trait locus for alcohol preference and is differentially expressed in alcohol-preferring and -nonpreferring rats. Proc. Natl. Acad. Sci. USA 100, 4690-4695.

Liang, T., Kimpel, M.W., McClintick, J.N., Skillman, A.R., McCall, K., Edenberg, H.J., Carr, L.G., 2010. Candidate genes for alcohol preference identified by expression profiling in alcohol-preferring and -nonpreferring reciprocal congenic rats. Genome Biol. 11, R11.

Liou, H.H., Tsai, M.C., Chen, C.J., Jeng, J.S., Chang, Y.C., Chen, S.Y., Chen, R.C., 1997. Environmental risk factors and Parkinson's disease: a case-control study in Taiwan. Neurology 48, 1583-1588.

Liu, J., Lewohl, J.M., Dodd, P.R., Randall, P.K., Harris, R.A., Mayfield, R.D., 2004. Gene expression profiling of individual cases reveals consistent transcriptional changes in alcoholic human brain. J. Neurochem. 90, 1050-1058.

Liu, J., Lewohl, J.M., Harris, R.A., Iyer, V.R., Dodd, P.R., Randall, P.K., Mayfield, R.D., 2006. Patterns of gene expression in the frontal cortex discriminate alcoholic from nonalcoholic individuals. Neuropsychopharmacology 31, 1574-1582.

Liu, J., Lewohl, J.M., Harris, R.A., Dodd, P.R., Mayfield, R.D., 2007. Altered gene expression profiles in the frontal cortex of cirrhotic alcoholics. Alcohol. Clin. Exp. Res. 31, 1460-1466.

Maraganore, D.M., de Andrade, M., Elbaz, A., Farrer, M.J., Ioannidis, J.P., Kruger, R., Rocca, W.A., Schneider, N.K., Lesnick, T.G., Lincoln, S.J., Hulihan, M.M., Aasly, J.O., Ashizawa, T., Chartier-Harlin, M.C., Checkoway, H., Ferrarese, C., Hadjigeorgiou, G., Hattori, N., Kawakami, H., Lambert, J.C., Lynch, T., Mellick, G.D., Papapetropoulos, S., Parsian, A., Quattrone, A., Riess, O., Tan, E.K., Van Broeckhoven, C., 2006. Collaborative analysis of alpha-synuclein gene promoter variability and Parkinson disease. JAMA 296, 661-670.

Mash, D.C., Ouyang, Q., Pablo, J., Basile, M., Izenwasser, S., Lieberman, A., Perrin, R.J., 2003. Cocaine abusers have an overexpression of alpha-synuclein in dopamine neurons. J. Neurosci. 23, 2564-2571.

Mash, D.C., Adi, N., Duque, L., Pablo, J., Kumar, M., Ervin, F.R., 2008. Alpha synuclein protein levels are increased in serum from recently abstinent cocaine abusers. Drug Alcohol Depend. 94, 246-250.

Mayfield, R.D., Lewohl, J.M., Dodd, P.R., Herlihy, A., Liu, J., Harris, R.A., 2002. Patterns of gene expression are altered in the frontal and motor cortices of human alcoholics. J. Neurochem. 81, 802-813.

Mayfield, R.D., Harris, R.A., Schuckit, M.A., 2008. Genetic factors influencing alcohol dependence. Br. J. Pharmacol. 154, 275-287.

Menza, M., 2000. The personality associated with Parkinson's disease. Curr. Psychiatry Rep. 2, 421-426.

Morano, A., Jimenez-Jimenez, F.J., Molina, J.A., Antolin, M.A., 1994. Risk-factors for Parkinson's disease: case-control study in the province of Caceres, Spain. Acta Neurol. Scand. 89, 164-170.

Morozova, N., O’Reilly, E.J., Ascherio, A., 2008. Variations in gender ratios support the connection between smoking and Parkinson's disease. Mov. Disord. 23, 1414-1419.

Nestler, E.J., Aghajanian, G.K., 1997. Molecular and cellular basis of addiction. Science 278, 58-63.

Newman, R.E., Soldatenkov, V.A., Dritschilo, A., Notario, V., 2002. Poly(ADP-ribose) polymerase turnover alterations do not contribute to PARP overexpression in Ewing's sarcoma cells. Oncol. Rep. 9, 529-532.

Noyce, A.J., Bestwick, J.P., Silveira-Moriyama, L., Hawkes, C.H., Giovannoni, G., Lees, A.J., Schrag, A., 2012. Meta-analysis of early nonmotor features and risk factors for Parkinson disease. Ann. Neurol. 72, 893-901.

Oksman, M., Tanila, H., Yavich, L., 2006. Brain reward in the absence of alphasynuclein. Neuroreport 17, 1191-1194.

O’Reilly, E.J., Chen, H., Gardener, H., Gao, X., Schwarzschild, M.A., Ascherio, A., 2009. Smoking and Parkinson's disease: using parental smoking as a proxy to explore causality. Am. J. Epidemiol. 169, 678-682.

Ostrerova, N., Petrucelli, L., Farrer, M., Mehta, N., Choi, P., Hardy, J., Wolozin, B., 1999. alpha-Synuclein shares physical and functional homology with 14-3-3 proteins. J. Neurosci. 19, 5782-5791.

Paganini-Hill, A., 2001. Risk factors for parkinson's disease: the leisure world cohort study. Neuroepidemiology 20, 118-124.

Palacios, N., Gao, X., O’Reilly, E., Schwarzschild, M., McCullough, M.L., Mayo, T., Gapstur, S.M., Ascherio, A.A., 2012. Alcohol and risk of Parkinson's disease in a large, prospective cohort of men and women. Mov. Disord. 27, 980-987.

Petersen, K., Olesen, O.F., Mikkelsen, J.D., 1999. Developmental expression of alphasynuclein in rat hippocampus and cerebral cortex. Neuroscience 91, 651-659.
Pietrzykowski, A.Z., Friesen, R.M., Martin, G.E., Puig, S.I., Nowak, C.L., Wynne, P.M., Siegelmann, H.T., Treistman, S.N., 2008. Posttranscriptional regulation of BK channel splice variant stability by miR-9 underlies neuroadaptation to alcohol. Neuron 59, 274-287.

Polymeropoulos, M.H., Lavedan, C., Leroy, E., Ide, S.E., Dehejia, A., Dutra, A., Pike, B., Root, H., Rubenstein, J., Boyer, R., Stenroos, E.S., Chandrasekharappa, S. Athanassiadou, A., Papapetropoulos, T., Johnson, W.G., Lazzarini, A.M. Duvoisin, R.C., Di Iorio, G., Golbe, L.I., Nussbaum, R.L., 1997. Mutation in the alpha-synuclein gene identified in families with Parkinson's disease. Science 276, 2045-2047.

Qin, Y., Ouyang, Q., Pablo, J., Mash, D.C., 2005. Cocaine abuse elevates alphasynuclein and dopamine transporter levels in the human striatum. Neuroreport $16,1489-1493$

Reich, T., Edenberg, H.J., Goate, A., Williams, J.T., Rice, J.P., Van Eerdewegh, P., Foroud, T., Hesselbrock, V., Schuckit, M.A., Bucholz, K., Porjesz, B., Li, T.K., Conneally, P.M., Nurnberger Jr., J.I., Tischfield, J.A., Crowe, R.R., Cloninger, C.R., Wu, W., Shears, S., Carr, K., Crose, C., Willig, C., Begleiter, H., 1998. Genome-wide search for genes affecting the risk for alcohol dependence. Am. J. Med. Genet. 81, 207-215.

Ridge, J.P., Ho, A.M., Innes, D.J., Dodd, P.R., 2008. The expression of NMDA receptor subunit mRNA in human chronic alcoholics. Ann. N. Y. Acad. Sci. 1139, 10-19.

Saccone, N.L., Kwon, J.M., Corbett, J., Goate, A., Rochberg, N., Edenberg, H.J., Foroud, T., Li, T.K., Begleiter, H., Reich, T., Rice, J.P., 2000. A genome screen of maximum number of drinks as an alcoholism phenotype. Am. J. Med. Genet. 96, 632-637.

Sathyan, P., Golden, H.B., Miranda, R.C., 2007. Competing interactions between micro-RNAs determine neural progenitor survival and proliferation afte ethanol exposure: evidence from an ex vivo model of the fetal cerebra cortical neuroepithelium. J. Neurosci. 27, 8546-8557.

Schaefer, A., O'Carroll, D., Tan, C.L., Hillman, D., Sugimori, M., Llinas, R., Greengard, P., 2007. Cerebellar neurodegeneration in the absence of microRNAs. J. Exp. Med. 204, 1553-1558.

Schratt, G.M., Tuebing, F., Nigh, E.A., Kane, C.G., Sabatini, M.E., Kiebler, M., Greenberg, M.E., 2006. A brain-specific microRNA regulates dendritic spine development. Nature 439, 283-289.

Scott, D., Roy, S., 2012. Alpha-Synuclein inhibits intersynaptic vesicle mobility and maintains recycling-pool homeostasis. J. Neurosci. 32, 10129-10135.

Self, D.W., Nestler, E.J., 1998. Relapse to drug-seeking: neural and molecular mechanisms. Drug Alcohol Depend. 51, 49-60.

Seo, J.H., Rah, J.C., Choi, S.H., Shin, J.K., Min, K., Kim, H.S., Park, C.H., Kim, S., Kim, E.M., Lee, S.H., Lee, S., Suh, S.W., Suh, Y.H., 2002. Alpha-synuclein regulates neuronal survival via Bcl-2 family expression and PI3/Akt kinase pathway. Faseb J. 16, 1826-1828.

Sidhu, A., Wersinger, C., Moussa, C.E., Vernier, P., 2004. The role of alpha-synuclein in both neuroprotection and neurodegeneration. Ann. N. Y. Acad. Sci. 1035 250-270.

Sotiriou, S., Gibney, G., Baxevanis, A.D., Nussbaum, R.L., 2009. A single nucleotide polymorphism in the $3^{\prime} \mathrm{UTR}$ of the SNCA gene encoding alpha-synuclein is a new potential susceptibility locus for Parkinson disease. Neurosci. Lett. 461, 196-201.

Spillantini, M.G., Goedert, M., 2000. The alpha-synucleinopathies: Parkinson's disease, dementia with Lewy bodies, and multiple system atrophy. Ann. N. Y. Acad. Sci. 920, 16-27.

Tan, E.K., Matsuura, T., Nagamitsu, S., Khajavi, M., Jankovic, J., Ashizawa, T., 2000 Polymorphism of NACP-Rep1 in Parkinson's disease: an etiologic link with essential tremor? Neurology 54, 1195-1198.

Tapocik, J.D., Solomon, M., Flanigan, M., Meinhardt, M., Barbier, E., Schank, J.R. Schwandt, M., Sommer, W.H., Heilig, M., 2012. Coordinated dysregulation of mRNAs and microRNAs in the rat medial prefrontal cortex following a history of alcohol dependence. Pharmacogenomics J..

Thacker, E.L., O'Reilly, E.J., Weisskopf, M.G., Chen, H., Schwarzschild, M.A. McCullough, M.L., Calle, E.E., Thun, M.J., Ascherio, A., 2007. Tempora relationship between cigarette smoking and risk of Parkinson disease. Neurology 68, 764-768.

Touchman, J.W., Dehejia, A., Chiba-Falek, O., Cabin, D.E., Schwartz, J.R., Orrison, B.M. Polymeropoulos, M.H., Nussbaum, R.L., 2001. Human and mouse alphasynuclein genes: comparative genomic sequence analysis and identification of a novel gene regulatory element. Genome Res. 11, 78-86.

Tzivion, G., Luo, Z., Avruch, J., 1998. A dimeric 14-3-3 protein is an essential cofactor for Raf kinase activity. Nature 394, 88-92.

Van Steenwyk, G., Janeczek, P., Lewohl, J.M., 2013. Differential effects of chronic and chronic-intermittent ethanol treatment and its withdrawal on the expression of miRNAs. Brain Sci. 3, 744-756.

Walker, S.J., Grant, K.A., 2006. Peripheral blood alpha-synuclein mRNA levels are elevated in cynomolgus monkeys that chronically self-administer ethanol. Alcohol 38, 1-4.

Wang, L.L., Zhang, Z., Li, Q., Yang, R., Pei, X., Xu, Y., Wang, J., Zhou, S.F., Li, Y., 2009 Ethanol exposure induces differential microRNA and target gene expression and teratogenic effects which can be suppressed by folic acid supplementation. Hum. Reprod. 24, 562-579.

Wersinger, C., Sidhu, A., 2003. Attenuation of dopamine transporter activity by alpha-synuclein. Neurosci. Lett. 340, 189-192.

WHO, 2004. Global Status Report on Alcohol. Department of Mental Health and Substance Abuse, WHO, Geneva.

Williams, J.T., Begleiter, H., Porjesz, B., Edenberg, H.J., Foroud, T., Reich, T., Goate, A. Van Eerdewegh, P., Almasy, L., Blangero, J., 1999. Joint multipoint linkage 
24 June 2013

analysis of multivariate qualitative and quantitative traits. II. Alcoholism and event-related potentials. Am. J. Hum. Genet. 65, 1148-1160.

Withers, G.S., George, J.M., Banker, G.A., Clayton, D.F., 1997. Delayed localization of synelfin (synuclein, NACP) to presynaptic terminals in cultured rat hippocampal neurons. Brain Res. Dev. Brain Res. 99, 87-94.

Xia, Y., Rohan de Silva, H.A., Rosi, B.L., Yamaoka, L.H., Rimmler, J.B., Pericak-Vance, M.A., Roses, A.D., Chen, X., Masliah, E., DeTeresa, R., Iwai, A., Sundsmo, M. Thomas, R.G., Hofstetter, C.R., Gregory, E., Hansen, L.A., Katzman, R., Thal, L.J., Saitoh, T., 1996. Genetic studies in Alzheimer's disease with an NACP/Lsynuclein polymorphism. Ann. Neurol. 40, 207-215.

Yadav, S., Pandey, A., Shukla, A., Talwelkar, S.S., Kumar, A., Pant, A.B., Parmar, D., 2011. MiR-497 and miR-302b regulate ethanol-induced neuronal cell death through BCL2 protein and cyclin D2. J. Biol. Chem. 286, 37347-37357.
Yavich, L., Tanila, H., Vepsalainen, S., Jakala, P., 2004. Role of alpha-synuclein in presynaptic dopamine recruitment. J. Neurosci. 24, 11165-11170.

Zahr, N.M., Kaufman, K.L., Harper, C.G., 2011. Clinical and pathological features of alcohol-related brain damage. Nat. Rev. Neurol. 7, 284-294.

Zhang, L, Zhang C., Zhu, Y, Cai, Q Chan, P., Ueda, K., Yu, S., Yang H., 2008. Semiquantitative analysis of alpha-synuclein in subcellular pools of rat brain neurons: an immunogold electron microscopic study using a C-terminal specific monoclonal antibody. Brain Res. 1244, 40-52.

Ziolkowska, B., Gieryk, A., Wawrzczak-Bargiela, A., Krowka, T., Kaminska, D. Korkosz, A., Bienkowski, P., Przewlocki, R., 2008. Alpha-Synuclein expression in the brain and blood during abstinence from chronic alcohol drinking in mice. Neuropharmacology 54, 1239-1246. 